\title{
Isolation of Monilinia fructigena from the Idared Apple Variety in Order to Test Some Bio-Fungicides ${ }^{+}$
}

\author{
Camelia Ungureanu ${ }^{1, *}$, Liliana Cristina Soare ${ }^{2}$, Mirela Calinescu ${ }^{3}$, Irina Fierascu 4 \\ and Radu Claudiu Fierascu ${ }^{4}$ \\ 1 Faculty of Applied Chemistry and Materials Science 1-7, University “Politehnica” of Bucharest, Polizu Str., \\ 011061 Bucharest, Romania \\ 2 University of Pitesti, 1 Targul din Vale Street, 110040 Pitesti, Arges County, Romania; \\ soleil_cri@yahoo.com \\ 3 Research Institute for Fruit Growing Pitesti, 402, Marului Str., 117450 Maracineni, Arges County, Romania; \\ elacalinescu@yahoo.com \\ 4 National Institute for Research \& Development in Chemistry and Petrochemistry - ICECHIM, \\ 202 Spl. Independentei, 060021 Bucharest, Romania; irina.fierascu@icechim.ro (I.F.); \\ fierascu.radu@icechim.ro (R.C.F.) \\ * Correspondence: ungureanucamelia@gmail.com \\ + Presented at the 16th International Symposium "Priorities of Chemistry for a Sustainable Development" \\ PRIOCHEM, Bucharest, Romania, 28-30 October 2020.
}

Published: 13 November 2020

Keywords: Monilinia fructigena; apple disease; fungi isolation; Idared variety; apple fruits

To test some bio-fungicides, isolation of Monilinia fructigena was carried out. Monilinia fructigena is a plant pathogen causing fruit rot in apples $[1,2]$.

The fungus strain was cultivated onto potato-dextrose agar from Sigma-Aldrich with the following composition: dextrose, $20 \mathrm{~g} / \mathrm{L}$, agar, $15 \mathrm{~g} / \mathrm{L}$, and potato extract, $4 \mathrm{~g} / \mathrm{L}$. Chloramphenicol antibiotic was used to avoid bacterial contamination. Experiences were effectuated using fruits of the Idared apple variety from the Research Institute for Fruit Growing Pitesti-Mărăcineni.

Morphological observations were taken based on colony, conidia, and conidiophore morphology and other morphological characters [3].

Monilinia fructigena (Figure 1) was isolated from infected apples (fruits) and grown on the potatodextrose agar culture medium with the goal to test some bio-fungicides.
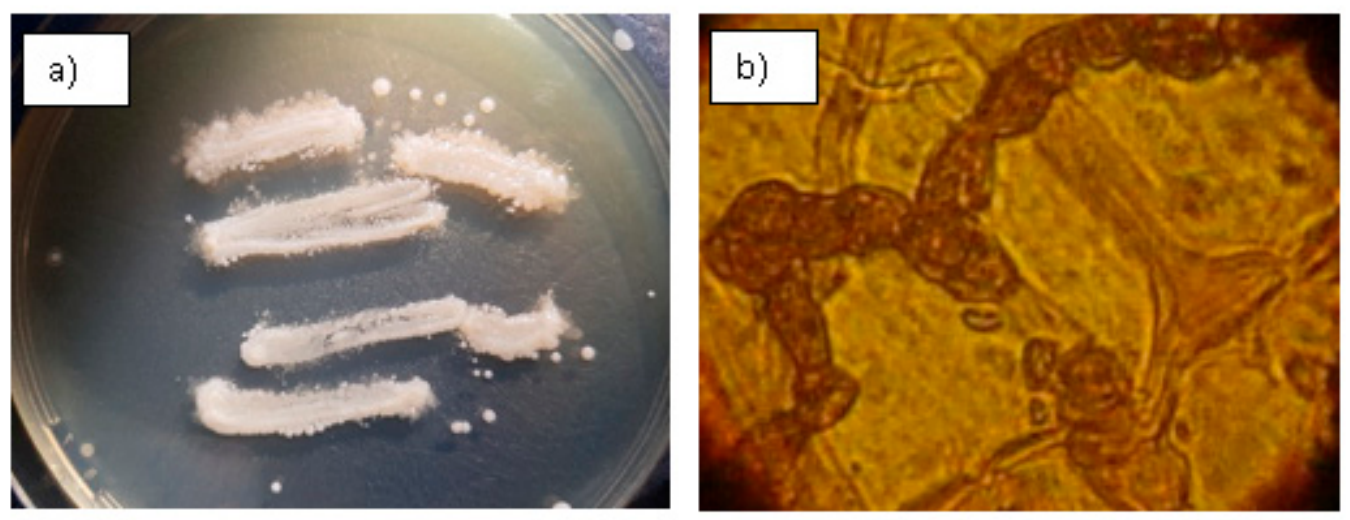

Figure 1. Monilinia fructigena (a); microscope view of Monilinia fructigena (b). 
Acknowledgments: This work was supported by a grant of the Romanian Ministry of Research and Innovation, CCCDI-UEFISCDI, project number PN-III-P1-1.2-PCCDI-2017-0332"/Project 3, contract 6PCCDI/2018, within PNCDI III.

\section{References}

1. Synopsis of Fungi Listed as Regulated Plant Pests by the USDA Animal and Plant Health Inspection Service: Notes on Nomenclature, Disease, Plant Hosts, and Geographic Distribution. Available online: www.plantmanagementnetwork.org/pub/php/diagnosticguide/2006/fungi (accessed on 5 May 2006).

2. EPPO. Diagnostic Protocols for Regulated Pests. Monilinia fructicola. PM 7/18 (1). EPPO Bull. 2003, 33, 281288. Available online: http://www.eppo.org (accessed on 15 September 2020).

3. Xu, X.M.; Robinson, J.D. Epidemiology of brown rot (Monilinia fructigena) on apple: infection of fruits by conidia. Plant Pathol. 2000, 49, 201-206.

Publisher's Note: MDPI stays neutral with regard to jurisdictional claims in published maps and institutional affiliations.

(C) 2020 by the authors. Licensee MDPI, Basel, Switzerland. This article is an open access article distributed under the terms and conditions of the Creative Commons Attribution (CC BY) license (http://creativecommons.org/licenses/by/4.0/). 